\title{
Automation in the Unloading and Loading Process of Hot Rolled Coil Using Workspace Simulation Software: a Review
}

\author{
Kunal A. Patil*, S.B. Jaju**, B. G. Achmare*** \\ *Department of Mechanical Engineering, GHRCE, Rashtrasant Tukadoji Maharaj Nagpur University \\ **Professor at Department of Mechanical Engineering, GHRCE, Nagpur, MH, India \\ ****Deputy General Manager, JSW ISPAT steel limited, Kalmeshwar, Nagpur, MH, India
}

\begin{tabular}{l} 
Article Info \\
\hline Article history: \\
Received Nov 14, 2015 \\
Revised Jan 27, 2016 \\
Accepted Feb 12, 2016 \\
\hline
\end{tabular}

\section{Keyword:}

Automation

Hot Rolled Coil

Robotics

Unloading and Loading

\begin{abstract}
The aim of this paper is to confirm the importance of unloading and loading process of hot rolled coil and automation in manufacturing industry. This paper describes about the different systems which are used in various ISPAT industries for material handling purpose or lifting the heavy coils. There are six main systems which are used in industries for material handling purpose. After studying all these systems, we will propose one system which is more beneficial than other systems. Later in this paper we will also study the introductory part of the workspace simulation software, its features, benefits and applications. The objective of this project is to overcome the problems at industry by designing and simulating a robot arm to perform the task. By simulating, the process of unloading and loading of hot rolled coil can perform more effectively. Workspace LT is the software used in this project.
\end{abstract}

Copyright $(2016$ Institute of Advanced Engineering and Science. All rights reserved.

Corresponding Author:

Kunal Abhay Patil,

Departement of Mechanical Engineering,

Rashtrasant Tukadoji Maharaj Nagpur University,

Chhatrapati Shivaji Maharaj Administrative Premises, Ravindranath Tagore Marg, Nagpur 440001

Email: kunnalpatil10@gmail.com

\section{INTRODUCTION}

In most of the ISPAT industries the unloading and loading of hot rolled coil carried with the help of different cranes and systems. The important systems are, C hook system, dual arm system, magnetic system, hydraulic system, suction or vacuum system and slab hand crane. These all systems have different lifting capacities and features. And as per the requirement of the work they are used. In many industries where heavy load material haling is done, the hydraulic system is used. We will see all the details about these systems in this paper and try to conclude one system which is more efficient.

There are two types of workspace simulation software. One is workspace LT which is used for educational simulation solutions and other is workspace 5 which is used for industrial simulation solutions. We will see all the details of workspace LT further in this paper.

Robotic simulation is a approach that involves the design, analysis and offline programming of robotic work cells. It captures the visualization of how the robot moves based on series of predefined geometric points. The simulation is basically depending upon CAD software like CATIA. Simulation has many advantages which we are going to see next.

\section{DIFFERENT SYSTEMS USED IN ISPAT INDUSTRIES:-}

\subsection{Chook System}

In the Figure 1 you can see a single arm system or $\mathrm{C}$ hook system which is used for lifting the coil. The lifting capacity of this system is ranges from 10-40 tonne. It uses a hollow space inside the coil for lifting 
purpose. This system allows close stacking of hot rolled coil which results in maximizing floor space. C hook system can handle wide range of coil width for lifting. This system is specially design for heavy materials like hot rolled coil.

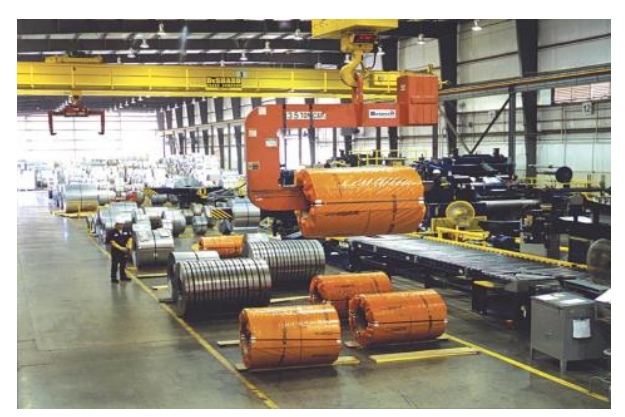

Figure 1. C hook System

\subsection{Dual Arm System}

This is the another system which can be used for lifting or moving the coil from one place to another. The lifting capacity of this system is 15-30 tonne. As the name suggest, there are two arms or tongs which is used to lift the coil. This motorized leg drives helps in increasing the efficient handling of coils. This system also allows close stacking of coils resulting in maximize floor space. These arms have curved lifting pads so that the coil won't get damage by its edge. The slide wear guides can be replace easily.

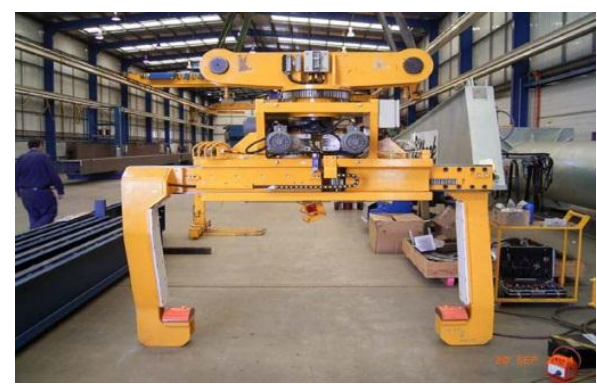

Figure 2. Dual Arm System

\subsection{Magnetic System}

There is one another system for the lifting of hot rolled coil named as magnetic system. The lifting capacity of this system is about 15 tonne. Magnetic system is the easiest and fastest in handling of coils. It is also a very economical method of handling the coils. As the magnet is used for lifting the coil, there is no possibility of damage to the coils. Low storage space is required. To operate this system, less manpower is required comparatively to other systems.

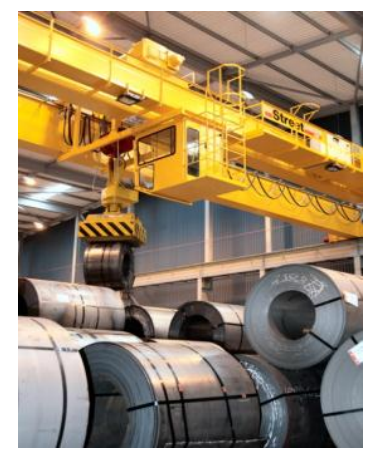

Figure 3. Magnetic System 


\subsection{Hydraulic System}

Hydraulic system is the most widely system used in the industry for various purpose like stacking of materials, unloading and loading of bulky die punches, handling of heavy jobs to various machines like CNC, milling. It is able to move trucks and loads to desired place. The lifting capacity of this system is 5- 40 tonne. It has many features such as low noise. The efficiency of hydraulic system is very high and it is easy to operate, less maintenance.

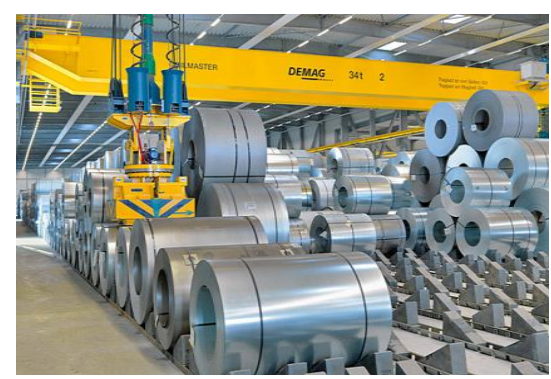

Figure 4. Hydraulic System

\subsection{Vacuum System}

Suction system or vacuum system is another way by which we can lift the coil. The capacity of this system is 20 tonne. The stainless steel is used for picking up head. In case of any accidental collision there is emergency stop device available for safety purpose. The suction cups which are used for lifting are made up of natural rubber. The venturimetro device is used to create a vacuum effect. The sensors are installed to detect the oresence of the product which we have to lift. On the machine, the electrical and pneumatic equipments are set.

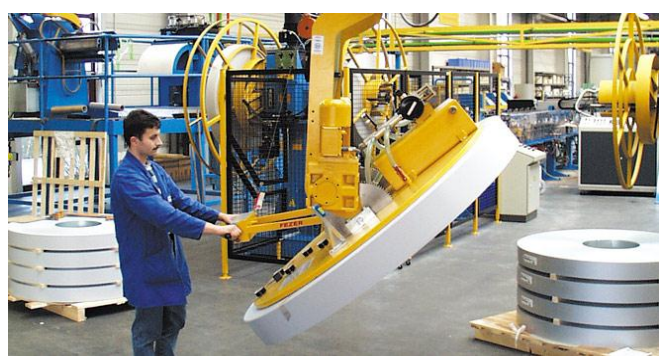

Figure 5. Vacuum System

\subsection{Slab Hand Crane}

One more system which is used for the lifting heavy duty materials is slab hand crane. The lifting capacity of this crane is very high that is 180 tonne. For single or multiple slab handling, the crane can be equipped with mechanical or hydraulic tongs. To increase the rate of production, the gripping speed is reduced to minimum. The crane travelling speed is $150 \mathrm{~m} / \mathrm{min}$.

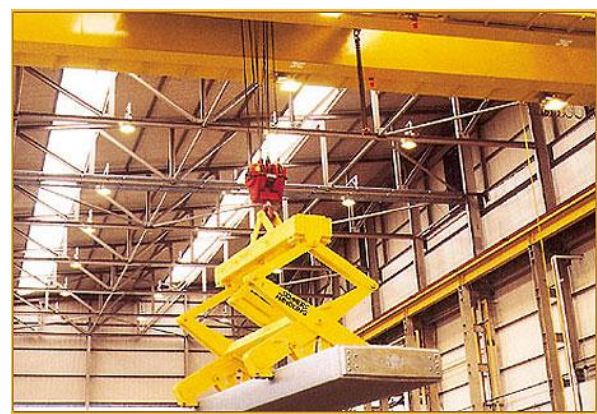

Figure 6. Slab Hand Crane 


\section{AUTOMATION IN INDUSTRY}

In robotics and automation industry sector, the construction industry is one of the most unfamiliar R\&D fields. The construction industry is one of the largest and oldest economy sector. In the industrialized countries like US and Japan, the contribution of industry to their GDP is about 7 to $10 \%$ but in comparison to the recent advanced technology, it seems that the level of automation in construction is still very low. This is the reason why all researchers and companies must take new efforts to increase level of automation in industry sector.

In many industry sectors, construction is one of the most important economy aspect. More competition, less skilled labor and technology advancement are forcing to make rapid changes in construction automation. All these aspects motivates for the automation in the industry. Heavy machines such as bulldozers, excavators are very common in construction. Research development have shown the promise of automation in construction industry but still the fully automation in construction site is dream of some civil engineers.

In manufacturing industry, the implementation of robot has been a value added entity. Robotic simulation is used to visualize the entire robotic movement of arms based on series of predefined geometric points, layout checking and robot's reach ability by generating workplace, collision and near miss detection and monitoring on the cycle time upon completing the task. The researcher Zomaya, explain the role of robot in industry and some of them are cost of labors, increment in flexibility, versatility and displace human working in hazardous and impractical environment.

A robot is one of the most popular issue on robotic field. A robotic arm which is used in industry may have single arm or dual arm. The dual arm robot has two arms same as human. The dual arm robot is able to perform more complex task than the single arm robot, and some of the tasks are handling of materials or pick and place operation. One can replace human by robot in industry by considering its features and advantages.

\section{WORKSPACE LT}

Workspace is a software which is used for the simulation purpose. Simulation for robotics and manufacturing automation for industry and for education. There are mainly two types of workspace simulation software workspace LT and workspace 5. Out of two the workspace LT is used for the purpose of educational simulation solutions and the another one workspace 5 is used for the industrial simulation solutions. In this paper we will discuss about the workspace LT software because we will be using this software in our project work.

Workspace LT is a industrial grade simulation software which is used for educational purpose. For teaching the concepts and robot's programming it provides the solution and other manufacturing automation equipments. It provides full offline programming and ability to simulate complex workcells with multiple robots and automation devices. It also offers you to make use of limited robot lab resources.

This workspace LT software has many features such as CAD modeling, 3D mouse support, offline programming and simulation. The CAD modeling has capabilities of creating 3D model, manipulation and modification. It eliminates the necessity of additional Cad software to create geometry. It can import data from other CAD software as well. Another important feature is 3D mouse support. It is just like gripping the model in your fingers by reaching into the screen. You can zoom in, zoom out, rotate and pan is as if you are holding the model in your hand. This 3D mouse provides high level of control which is not possible by traditional mouse. Offline programming supports native robot languages. Some of currently supported languages are Arla, Rapid, Karel, TP, Val1, Val2 etc. One more feature of this software is simulation. In this accurate kinematic modeling of robots and mechanism is done. It also has collision detection feature. By identifying the interference it can prevent collision.

Using this software has many benefits such as minimum cost, there is minimizing in production downtime, the flexibility is improved and cycle time as well. It can save programming time and improve path accuracy with automatic path feature. So this is the brief introduction about the workspace LT simulation software.

\section{CONCLUSION}

In this paper, we discussed the various systems that are being used in industry for unloading and loading purpose. As the weight of hot rolled coil is much more and considering the features, we are suggesting robotic arm for the process of unloading and loading of hot rolled coil which will be operated by hydraulic system. And we have also discussed about the advantages of the automation in the industry using 
robotic arm. Robotic simulation provides highly detailed 3 dimension view of work cell and allow user to identify any interference between robot and object. It also provided with cycle time monitoring to verify how long a robot will complete a given task. Programming a robot with minimum cycle time will ensure higher productivity of a production. And further in this project we will design and simulate the hydraulic system as per the requirement.

\section{ACKNOWLEDGEMENT}

I wish to epress my deep sense of gratitude and honor towards my respected guide Dr. S.B. Jaju for his inspiring guidance and encouragement. Special thanks to Mr. Vivek Vaidya for his technical guidance and support.

\section{REFERENCES}

[1] Nory Afzan Mohd Johari, Habibollah Haron, Abdul Syukor Mohamad Jaya , Robotic Modeling And Simulation Of Palletizer Robot Using Workspace5, Computer Graphics, Imaging And Visualisation (Cgiv 2007)07695-2928-3/07 \$25.00 @ 2007

[2] Nitin Chaudhari And Vilas B Shinde, Recent Trends In Robotic End Of Arm Tooling (Gripper), Issn 2278 - 0149 Www.Ijmerr.Com Vol. 3, No. 2, April 2014@ 2014 Ijmerr.

[3] Zuraini Sukimin, Habibollah Haron, Designing And Simulating Chopping Process Using Workspace5, 978-0-7695$3136-6 / 08 \$ 25.00$ @ 2008 Ieee

[4] Chanhun Park, Hyunmin Do, Taeyong Choi And Jinho Kyung, Development Of Dual Arm Robot Platform For Automatic Assembly, 2014 14th International Conference On Control, Automation And Systems (Iccas 2014)Oct. 22-25, 2014 In Kintex, Gyeonggi-Do, Korea.

[5] Rafal Burdzik, Maria Ciesla, Alexsandar Sadkowski, Cargo Loading And Unloading Efficiency Analysis In Multimodal Transport, Intermodal Transportreviewsubmitted: Aug. 12, 2013approved: July 8, 2014

[6] Quang Ha, Miguel Santos, Quang Nguyen, David Rye, And Hugh Durrant-Whyte, Robotic Excavation In Construction Automation, Ieee Robotics And Automation Magazine March 2002

[7] Ernesto Gambao, Carlos Balaguer, Robotics And Automation In Construction, Ieee Robotics And Automation Magazine March 2002

\section{WEBSITES:-}

[1] www.caldwellinc.com

[2] www.walkermagnet.com

[3] www.ylmequipmentmachinery.com

[4] www.europackitaly.com

[5] www.konecranes.com

\section{BIOGRAPHIES OF AUTHOR}

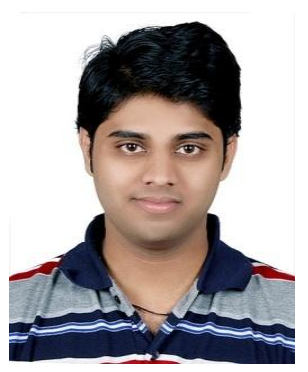

Kunal Patil obtained his bachelor degree in Mechanical Engineering from Pinpri Chinchwad College of Engineering, Pune on 2014. Presently he is a Master Degree student (CAD/CAM) In the Department of Mechanical Engineering, G.H. Raisoni college of Engineering, Nagpur, Maharashtra, India. 